\title{
Image and visual culture after the pictorial turn: an outsider's note
}

\section{Jan Baetens}

Visual culture is the name of a now well-established academic field, the disciplinary and symbolic status of which nevertheless remains uncertain. Structured around the notion of the 'pictorial turn', visual culture has encountered various critiques, which impose on the field to state of permanent revision and repositioning. This article attempts to give an overview of some recent theoretical debates and sketches some perspectives for further research.

\section{Introduction}

As a literary scholar, strongly interested by questions of theory and history but still committed to oldfashioned habits of close-reading, I have been challenged for many years now by the blurring of boundaries between my own discipline and the newer and apparently boundless fields of cultural studies and visual culture. These encounters have indisputably had an impact on my own research agenda. The objects I now work on are now marked by hybrid structures and intermediality (for instance comics, the genre of novelisation, and the photo-novel; Baetens 2006, 2008, 2012a). In a similar vein, I have tried to question issues of interdisciplinary contact, conflict, dialogue and exchange (Baetens and Blatt 2008; Plesh, MacLeod and Baetens 2011; Baetens 2012b). Yet despite these efforts, the very notion of image, the conceptual, cultural, historical, philosophical and ideological complexity of which has been a key topic in literary studies since the seminal book by WJT Mitchell on iconology (Mitchell 1985), has never ceased to represent a thorny problem. It has proven possible, and dramatically fruitful, to study literature in a perspective of intermediality (Rajewsky 2005) and to study: 1) words as images (for instance in visual poetry); 2) words alongside images (for instance in illustrated books); and 3) words referring to images (as intertextual mentions of non-textual material). Nevertheless, the notion of image continues to be an open and exciting, yet challenging, question. In the following pages, I want first to revisit earlier discussions of the word and image framework, and then, inspired by recent publications in image studies, to sketch some ideas I 
consider promising for reading the image in disciplines that are not primarily focusing on the visual but which can no longer discard the image as external to their own field.

\section{The Verbal and the Visual: an Eternal Story?}

What an image actually is, and how and why we should study it, is no longer a question that can be answered in just one way. We can only observe that there exist countless ways of conceiving the image today, and the methodological and theoretical discussions launched by the success of interdisciplinary approaches such as cultural studies have produced a dramatic increase in this plurality. It is now possible to distinguish between approaches such as: 1) analysis based on the material properties of the image: fixed versus mobile, analogous versus digital, 2D versus 3D;2) analysis based on its various uses: looking, watching, copying, appropriating, displaying, destroying, hiding, collecting; and 3) analysis based on the cultural value or social status of images: unique versus reproduced, high versus low, original versus banal, protected by copyright laws or abandoned to the public domain or the curious set of the so-called 'orphan' objects. Any student or scholar can easily continue these kinds of lists, which are always on the verge of becoming as heterogeneous as the famous encyclopedia of Chinese animals invented by Borges, and discussed by Michel Foucault in the opening chapter of The Order of Things (1970).

In Western culture, however, there is a well-established stereotype that forces scholars, willingly or not, to analyse the image by comparing it with the element that seems to be its opposite: words, language, writing, text. Even when the very difference between the verbal and the iconic is challenged (and we all know that there are numerous attempts to blur the boundaries between visible and written signs) or when the merger of these two semiotic modes is pursued as a model or an ideal (and here as well we are all aware of the fact that hybridisation has become the fashion of the day), the fundamental horizon of all these comparisons remains the word and image couple. Other dichotomies may intervene or be added to it, such as the distinction between the optical and the haptic, between seeing and touching, or image and sound. Yet, I suggest, their impact and importance will never be the same as the key tension between the image and the word. Since the Greeks and the Romans, the Western 
tradition is put under the aegis of the discussion on the sister arts, whose kinship is also a matter of competition: no ut pictura poesis ('as is painting, so is poetry') without paragone (an Italian word whose literal meaning is 'comparison', but which actually refers to the battle of the arts, which are all striving for hegemony).

The crucial difference between word and image helps introduce a first basic distinction. However defined, discussed or implemented, an image will not be the same in the sphere of disciplines that were traditionally text-oriented as in disciplines usually seen as image-based. In the case of imagebased disciplines, to start with, there has certainly been resistance to the introduction of new methods: many art historians remain committed to iconological approaches, though we must acknowledge that the field of iconology is anything but static (Panofsky is not Warburg, Gombrich is not Belting). Equally, there has been strong resistance toward the paradigm shift represented by cultural studies or new museum studies, in which the basic concern is no longer to study what or how to exhibit, but a focus on why-questions (Macdonald 2010). The key term here is visual culture, and many art historians have long regarded this form of visual studies as lacking depth, technical skills and seriousness; in short, in their eyes, a weak version of the non-science which is cultural studies. But, as powerfully argued by David Joselit, visual culture is not only a contemporary, fashionable, politically correct way of doing visual analysis, it is also and above all a new way of studying images:

Within the humanities, studies in visual culture have arisen as one type of response to the challenge of tracking the 'social life of things'. Recent scholarship in this field has been structured along four axes: method, archive, technology, and reception. Methodologically, visual culture is said to mimic, even to envy, the science of anthropology, whose object is not limited to the artist's production but rather embraces the rituals, practices, and visual artefacts of an entire culture. This shift in object of study is closely related to an expansion of aesthetic archives beyond the oeuvre of individual fine artists to encompass works of corporate commercial art ranging from film to comics and advertisements. Much work in visual culture is premised on a theory 
of history in which new media (successively, photography, film, radio, television, and the Internet) are shown to produce new modes of visuality. This emphasis on technologies of vision has helped to consolidate lively studies of spectatorship in which meaning is associated as much with the consumption as with the production of aesthetic works. (Joselit 2007, 31)

In the case of certain traditionally text-based disciplines, on the contrary, there has been much less resistance to this methodological and theoretical aggiornamento. Literary scholars, for instance, have been eager to embrace the visual or pictorial turn, even in their own field, and they have made major contributions to the study of this shift. Certain subfields of literary studies, such as narratology, have massively turned towards intermediality and cross-mediality: narrative is no longer studied in texts only, but in all possible media (Ryan 2004; for a critical view, see Eskelinen 2012). Probably under the lasting influence of semiotics in literary and cultural studies, these scholars have played an active role in attempts to theorise the notion of visual literacy, which has emerged as a companion term to the key notion of pictorial turn. Confronted with the rise of the image in today's society and communication, textual culture tries to catch up with the visual revolution that has taken place in modern and postmodern culture. The text tries to reinvent itself in the visual era, opening itself to new research in visual studies. However, such methodological and theoretical moves are not without their dangers, the main one being the more or less mechanical transfer of the already known (or at least the already familiar), namely the text, to the still to be learnt, namely the image. In this regard, it has become a kind of ritual to reiterate the critical warning by WJT Mitchell, at the very moment of his coining of the notion of the pictorial turn:

Whatever the pictorial turn is, then, it should be clear that it is not a return to naive mimesis, copy or correspondence theories of representation, or a renewed metaphysics of pictorial 'presence': it is rather a postlinguistic, post semiotic rediscovery of the picture as a complex interplay between visuality, apparatus, institutions, discourse, bodies, and figurality. It is the realization that spectatorship (the look, the gaze, the 
glance, the practices of observation, surveillance, and visual pleasure) may be as deep a problem as various forms of reading (decipherment, decoding, interpretation, etc.) and that visual experience or 'visual literacy' might not be fully explicable on the model of textuality. (Mitchell 1994, 16)

These caveats still hold today, and it would be pretentious to claim that visual scholarship is now beyond these issues. Various authors after Mitchell have taken stances against a certain way of studying the image, namely the lazy and 'easy way' exemplarily criticised by James Elkins in several of his books, but mainly in his essay Visual Studies: A Critical Introduction (2003) and the collective volume Visual Literacy (2008). Elkins condemns in the strongest possible terms what he considers the blindness of visual culture toward the real challenges of visual studies, such as, for instance, the necessity to tackle scientific and non-Western images, the obligation to supersede the selfcongratulatory attitudes of political correctness and the fashion for hybridisation; as well as the need to start a dialogue with the 'hard' sciences. He takes a similar stance on the notion of visual literacy, which is not to say, however, that an awareness of the limitations of the concept (for there is something inherently contradictory in the idea of 'reading' an image) should lead to a position of retreat, on the contrary. Elkins underlines the necessity to replace textual methods by visual methods in undergraduate teaching:

What is needed is a university-wide conversation on what might comprise an adequate visual introduction to the most pressing themes of contemporary culture. (...) Since the 1980s the rhetoric of images has become far more pervasive, so that it is now commonplace in the media to hear that we live in a visual culture, and get our information through images. It is time, I think, to take those claims seriously. They need to be taken out of graduate philosophy and history classrooms, and brought down the hall to the large lecture theaters where first-year students are taught the things the university thinks are necessary for a general education. It is time to consider the 
possibility that literacy can be achieved through images as well as texts and numbers.

(Elkins 2008, 4-5)

The direction such a 'university-wide conversation' might take remains unclear, not least because of the absence of any new hegemonic model (as can be inferred for instance from the dizzying diversity of research methods gathered in Margolis and Pauwels 2011). In what follows, I would like to defend three different yet complementary perspectives: first, the usefulness of thinking the novelty effect of images; second, the necessity of emphasising the consequences of the technological enhancement of images; third, the new forms of tension that occur from the apparent dichotomy of centre and periphery.

\section{Images as Novelty or Images and Change?}

New images are being produced almost routinely, and media change has become the norm rather than the exception. However, the ceaseless production of 'the next thing' in visual imagery has weakened rather than reinforced the Modernist credo of 'make it new' (Ezra Pound). Yet innovation is still an important driving force in culture, and it is therefore imperative to abandon the classic view of innovation in linear or teleological terms. In order to see the changes brought about by newness, it is no longer useful to describe how new media transform currently existing media in old media. Rather than discussing the changes of visual culture in terms of old and new, it might be interesting to reinterpret the image in terms of imageness, as proposed by Jacques Rancière. In The Future of the Image, a key publication in this regard, Rancière defines imageness as 'a particular regime of the articulation between the visible and the sayable' (Rancière 2007, 11). Hovering not only between the representable and the unrepresentable, but also between the sayable and the unsayable, the image as imageness becomes a more dynamic way of practicing the contacts between media as framed in classic or modern forms of media histories.

A good example of this approach is offered by Robin Kelsey's investigation of the apparently contradictory notion of 'archive style' (Kelsey 2007). Re-examining some major examples of 
nineteeth century United States survey photography, Kelsey questions the commonly accepted gap between the 'archive', i.e. the impersonal and strictly controlled collections of images, where no place whatsoever is left to the personal touch of the photographer, and the 'style', i.e. the highly individual and subjective properties of a body of images that exceed the archival straightjacket. Kelsey does not only underline the many border zones between archive and style, he also emphasises, in a Foucauldian spirit, the productive dimension of the archival constraints, which can 'force' the photographer to become an artist-practitioner who questions the limits of what can be shown in a given context. Novelty here is no longer the occurrence of something that has never been seen or shown, but the struggle of emerging forces to break out of the dominating set of rules, which tend to make the image to a large extent invisible and thus unsayable, for it goes without saying that both for Rancière and for Kelsey it would make no sense to postulate a strictly visual way of world-making. Several contributions in a recently published volume edited by Jacques Khalip and Robert Mitchell, Releasing the Image: From Literature to New Media (2011), make similar claims, as demonstrated by most authors' refusal of the image as essentially 'retinal', i.e. as something just to be seen or looked at. Visibility is never something that is given or self-evident. It cannot be taken for granted that images that are present are actually part of a process of meaning-making. Images must become visible, and the study of images has also to examine this becoming visible of the image. Before reading images, we must know what allows us to see them and what enables us to make sense of them.

This new research is in line with another idea of Rancière, namely the concept of sign production as the 'distribution of the sensible' (Rancière 2004), which expands the reflection on novelty and change to the field of subject matter. Indeed, according to Rancière, whose presence in the field may dramatically increase in the years to come, the selection of formal devices and thematic subjects does not reflect a world view but literally reshapes the world. The political power of an image has to do with this reshaping of the techniques and themes we currently rely upon when we want to 'say' the world, and each successful attempt to enlarge the repertoire has a potential emancipatory impact, since it allows for new forms of representation rather than just new types of images. The key question in this regard is then to know who has the right as well as the power to show this or that kind of image to this 
or that kind of public - a question not to be confused with traditional studies on censorship. Here as well, and once again in a spirit that borrows much from Foucault, the key issue is to examine how visual practitioners can 'stretch' the scope of what can be shown and said at a certain moment and in a certain context in order to help invent new ways of organising not just our ways of seeing but also our ways of experiencing and living the world.

\section{New reading Techniques for Technologically Enhanced Images?}

In another decisive publication by WJT Mitchell, the brief article 'There Are No Visual Media' (2005), the author makes a strong plea against any rigid visual taxonomies. 'There Are No Visual Media' is a critique of the reified sign taxonomies, based upon outdated ideas on words and images. Mitchell argues that no visual media are ever 'purely' visual media (images are intertwined with words as much as they are intertwined with other senses such as touching and feeling, for instance), while other, non-visual media are equally wrapped in visual aspects (reading a text, to give a very basic example, entails producing mental images). Reading images is a process that involves a much larger sensorium, which can no longer be dealt with along traditional semiotic lines. However, rather than trying to propose newer and more sophisticated tools to map the sensory ratios in the reading of images (looking, touching, hearing), Mitchell defends a more radical shift towards a greater awareness of what is now part of almost any image: technology, not only at the level of image production, but also at that of image storage, transformation, retrieval, distribution, perceiving and experiencing. Hence the insistence on the study of the material (both biological and technological) basis of the act of looking. According to Mitchell, who is very close to James Elkins' ideas on this problem, studying images should start (also) with studying optics, image engineering, new media and the hard cognitive studies.

It can be interesting to link this open comparative approach to a concept that until now has been used only in Francophone scholarship, but whose relevance for the larger field is crucial: the notion of cultural series, as proposed by André Gaudreault (who coined also, in collaboration with the American scholar Tom Gunning, the notion of 'cinema of attractions'). With the help of this concept 
(Gaudreault 2002), various types of images and media are no longer studied as independent forms or structures that change over time, but as non-teleologically evolving networks of media constellations and media productions. Such a network is not freely moving or evolving of course. Cultural series are always structured, albeit sometimes loosely, around a medium that is chosen as the starting point of the analysis and embedded in broader cultural and discursive frameworks. In more general terms, and to link the both synchronic and diachronic notion of cultural series with the already mentioned reflection on novelty and change, one might say that the model for the study of image here is that of synergy (the image as imageness embedded in cultural practices) rather than that of supersession (in which each new medium tends to take the place of a previously dominating 'old' medium).

This makes room for an expanded vision of image and imageness, which helps connect the image and its users, not in the phenomenological terms of the spectator and her relationship with the object that she is looking at, but in very material and social terms of the creation of communities that share a certain way of sharing images. Even in the case of digital image-making, it has now become rather commonplace to stress the importance of what one may call the expanded screen: digital-born images are no longer limited to the computer screen alone, they are integrated in 'real' environments outside the screen, which are giving birth to new forms of communication and agency (for an overview of these mutations, see Schäfer 2010). Obviously, this kind of research may offer new insights on the, perhaps overused, concept of interactivity. However, the role of the public can never be overestimated. As long demonstrated in science and technology studies, studying technological novelty should never be reduced merely to the supply side. What matters is the creative, open, and unforeseeable encounter with the user, whose reaction is never a simple response or answer to a query or a proposal but most of the times an active reappropriation and transformation of a new technological given (see Bijker et al. 1987, for a still valid overview of this kind of discussion).

\section{The Centrality of Minor Images}

Images are not only marked in temporal terms (old versus new) or invented, continued and transformed by technological changes and our reactions to them. They are also spatially marked, both 
literally and metaphorically. All images may be equal, but some are more 'central' than others, and the impact of this tension is fundamental. Images no less than texts, discourses and power relations are subject to the so-called spatial turn in critical and historical studies (for a good overview, see Berland 2010). One of the key motifs here will be glocalisation, the mutual reinvention of the local and the global. In the field of photography, glocalisation is now a solidly implanted topic (Baetens 2011), and the research in 'global iconology' has proven tremendously efficient in revitalising postcolonial studies. Recent scholarship is very keen to stress the importance of the spatial turn.

The most thorough example of such a reshaping of the spatially divided world through the study of the image is probably found in a recent monograph by Nicholas Mirzoeff, The Right to Look: A Counterhistory of Visuality (2011). The Right to Look is a (very) radical book, not only because of the political program that it defends but also, more methodologically speaking, because of its far-reaching refusal of any purely visual approach to the image. According to Mirzoeff, the visual culture has to do with a twofold relationship: first that between the gaze and the other, who is not an object that we look at but a subject capable of looking back; second that between looking and politics, which starts with the right of the one who is looked at to look back in his or her turn. From this point of view, visual culture is no longer a matter of images only, it is also and above all a matter of world-making. In this view, the notion of visuality points to the mechanisms that organise the world in order to reflect power relations. It is the structure that makes visible an underlying hegemony. Countervisuality, then, is less another way of seeing than the counter-hegemonic tactical moves aiming at dismantling hegemonic strategies. Looking back, for Mirzoeff, is not just looking back, it is questioning, destroying and modifying those worldviews that are imposed by Western visuality.

Mirzoeff's book is a good example of the spatial turn, but a study such as Global Icons (Ghosh 2011) is also worth mentioning. Global Icons is a book on the power of 'bio-icons', highly visible public figures capable of raising immense affects in local and global audiences (one of the examples used throughout the book is that of Mother Teresa). Bio-icons illuminate some other tendencies in the image studies mentioned above, such as, for instance, the intertwining of image and storytelling 
(Ghosh defines the image in terms of synergy between the visual and the verbal) or the shift from image as object to image as social practice (what interests Gosh is the social life of the image). However, it is the permanent interaction between the global, the local and the glocal that proves to be the most appealing dimension of bio-icons. Ghosh demonstrates that the power of images depends on their capacity of being universally circulated through mass media, yet the meaning of the image can only be negotiated in relationship to local agendas and policies.

A useful framework, to enlarge the spatial reading of the non-mainstream image is the notion of minor culture, first introduced in order to scrutinise the reuse of the literary models of a dominating language by its cultural minorities (Deleuze et Guattari 1986), and then extended to several visual fields, among which photography (Bleyen 2012). The three major characteristics of a minor literature, namely politicisation, collectivisation and deterritorialisation, are not only dramatically efficient when one wants to describe the meaning of certain images excluded from traditional studies of the image. They should also prove capable of making room for new readings of the major uses of visuality, which is certainly less monolithic and hegemonic than Deleuze and Guattari may have us believe. An essential question here will undoubtedly be the problem of what is or can be visually represented, and by whom (as such, this question seems utterly banal, but it has long been obfuscated by the exclusive fascination with the formal techniques of representing the visual).

\section{Conclusion}

Drawing clear-cut conclusions from the perspectives, studies and examples presented above remains extremely difficult. More than ever, it is easier to define the image in negative terms than in positive terms. It is now widely accepted that an image is not just something visual or retinal, just as it is no longer contested that images can only be seriously studies in a broader framework of non-visual media and non-visual objects. In this article, I have tried to foreground three major characteristics: 1) the idea of the image as a new way of distributing the sensible; 2) the idea of the image as something that is dramatically intertwined with technological structures and way of communicating; 3 ) the idea of the image as split between mainstream and marginal, major and minor forms and domains, and the 
manifold relationships that engage centre and periphery. It would be preposterous, however, for these lines of thinking, important as they may be, to be considered universal priorities on any research agenda in visual studies. The identification, selection and foregrounding of these, in my eyes, inextricably linked sets of questions clearly has something to do with my own background as a literary scholar, where similar interrogations have emerged in recent years. Nevertheless, given the fact that the image is now probably the most widely shared research object in the world, I hope that my proposals may prove useful to all those colleagues with whom I share the pleasure and the challenge of going back and forth between the image and the rest.

\section{References}

Baetens, J. 2006. Hergé écrivain. Paris: Flammarion.

Baetens, J., 2008. La novellisation. Du film au livre. Brussels: Les Impressions Nouvelles.

Baetens, J., ed. 2011. 'Glocal photography', History of Photography 35-2.

Baetens, J. 2012a. 'The photonovel: Stereotype as Surprise', History of Photography36-4 (forthcoming)

Baetens, J. 2012b. 'Visual studies/visual culture' in Thierry Lenain, Hubert Locher, Andrea Pinotti, Matthew Rampley, Charlotte Schoell-Glass, Kitty Zijlmans., eds., Art History and Visual Studies in Europe. Leiden: Bril, 91-106.

Baetens, J. and Blatt, A., eds, 2008. 'Writing and the Image Today', Yale French Studies No 114.

Baetens, J., ed. 2011. 'Glocal photography', History of Photography 35-2.

Berland, J., 2010. North of Empire: Essays on the Cultural Technologies of Space. Durham, NC: Duke University Press.

Bijker, B., Hughes, Th. et Pynch, T., eds, 1987. The Social Construction of Technological Systems: New Directions in the Sociology and History of Technology. Cambridge, Mass.: MIT Press.

Bleyen, M., ed., 2012. Minor Photography. Leuven: Leuven University Press.

Deleuze, G. Guattari, F. 1986. Kafka. Toward a Minor Literature. Minneapolis: University of Minnesota Press (French original: 1975).

Elkins, J. 2003. Visual Studies. A Skeptical Introduction. New York: Routledge. 
Elkins, J. , ed. 2008. Visual Literacy. New York: Routledge.

Eskelinen, M., 2012. Cybertext Poetics: The Critical Landscape of New Media Literary Theory. New York/London: Intellect.

Foucault, F. 1970. The Order of Things. New York: Vintage Books (French original: 1964).

Gaudreault, A. 2002. 'Du simple au multiple: le cinéma comme série de séries’, Cinémas: revue d'études cinématographiques/Cinema: Journal of Film Studies 13-1/2, 33-47.

Ghosh, B. 2011. Global Icons. Durham, NC, Duke University Press.

Joselit, D. 2007. Feedback. Television against Democracy. Cambridge, Mass.: MIT Press.

Kelsey, R. 2007. Archive Style: Photographs and Illustrations for U.S. Surveys, 1850-1890. University of California Press, Berkeley.

Margolis, E. and Pauwels, L., eds, 2011. The SAGE Handbook of Visual Research Methods. Los Angeles and London: Sage.

Mitchell, WJT. 1994. Picture Theory. Chicago: Chicago University Press.

--. 2005. 'There Are No Visual Media', Journal of Visual Culture 4: 2, 257-266.

Khalip, J., and Mitchell, R., eds. 2011. Releasing the Image. From Literature to New Media. Stanford: Stanford University Press.

Macdonald, S., ed. 2010. A Companion to Museum Studies. Malden, MA, and Oxford: WileyBlackwell

Mirzoeff, N. 2011. The Right to Look: A Counterhistory of Visuality. Durham, NC: Duke university Press.

Mitchell, WJT, 1985. Iconology. Image, Text, Ideology. Chicago: Chicago University Press.

Plesch, V., McLeod, C. and Baetens, J., eds, 2011. Efficacité/Efficacity: How to do things with words and images? Amsterdam/New York: Rodopi.

Rajewsky, I. 2005. 'Intermediality, Intertextuality, and Remediation: A Literary Perspective on Intermediality', Intermédialités 6, 43-64.

Rancière, R. 2004. The Politics of Aesthetics: The Distribution of the Sensible. London and New York: Continuum (French original 2000).

Rancière, R. (2007). The Future of the Image. London: Verso (French original 2003). 
Ryan, M.-L., 2004. Narrative across Media. The Language of Storytelling. Lincoln: Nebraska University Press.

Schäfer, J. (2010). 'Reassembling the Literary. Toward a Theoretical Framework for Literary Communication in Computer-Based Media', in Jörgen Schäfer and Peter Gendolla, eds, Beyond the Screen. Transformations of Literary Structures, Interfaces and Genres. Bielefeld: Transcript, $25-70$. 